\title{
A simple method for quantifying iodate and iodide fractions in solution using $\mathrm{Ag}^{+}$-impregnated activated carbon
}

\author{
Valtteri Suorsa ${ }^{1}\left[\right.$ Miho Otaki $^{1} \cdot$ Wenzhong Zhang $^{1} \cdot$ Juhani Virkanen $^{2} \cdot$ Risto Koivula $^{1}$
}

Received: 15 October 2019 / Published online: 25 February 2020

(c) The Author(s) 2020

\begin{abstract}
The speciation of iodine in environment must be known in order to properly assess its geological fate and to study potential remediation materials for the decontamination of water containing radioactive iodine. In this study, the utilization of silver-impregnated granular activated carbon for separation between two iodine species, iodate and iodide, from each other was studied in different solution matrices with batch and column experiments. A high separation of the iodine species was achieved in the high concentrations of interfering ions, e.g. chloride, and in both $\mu \mathrm{M}$ and trace iodine concentrations. The method is suitable for both radioactive and non-radioactive iodine.
\end{abstract}

Keywords Iodide $\cdot$ Iodate $\cdot$ Iodine species separation $\cdot$ HPLC-ICP-MS $\cdot$ Silver-impregnated activated carbon

\section{Introduction}

Iodine is an abundant element found in Earth's crust, atmosphere and oceans at notable concentrations. It is also a vital micronutrient to humans and other mammals as it is needed for the production of thyroid hormones and for the proper functioning of thyroid gland. For that reason, iodine is commonly added to table salt in the form of either iodide $\left(\mathrm{I}^{-}\right)$ or iodate $\left(\mathrm{IO}_{3}^{-}\right)$salt to supply populations the vital element $[1,2]$. On the other hand, radioactive isotopes of iodine, ${ }^{129} \mathrm{I}\left(\mathrm{t}^{1 / 2}=15.7 \mathrm{My}\right)$ and ${ }^{131} \mathrm{I}\left(\mathrm{t}^{1} / 2=8 \mathrm{~d}\right)$, pose a radiological threat in the case of a nuclear fallout as the radioactive iodine tends to absorb effectively to the thyroid gland and causing an elevated risk of thyroid cancer. From the longterm perspective, iodine's mobility in geochemical environments poses a major risk in nuclear waste disposal sites (i.e. [3]) and sets strict requirements for the long-term safety of

Electronic supplementary material The online version of this article (https://doi.org/10.1007/s10967-020-07061-4) contains supplementary material, which is available to authorized users.

Valtteri Suorsa

valtteri.suorsa@helsinki.fi

1 Department of Chemistry, University of Helsinki, A.I. Virtasen aukio 1, 00014 Helsinki, Finland

2 Department of Geosciences and Geography, University of Helsinki, Gustaf Hällströmin katu 2, 00014 Helsinki, Finland the final disposal concepts for spent nuclear fuel [4]. The key attribute determining the geochemical fate of iodine is its speciation [3].

Iodine's chemical and physical behaviour is strongly governed by its speciation. In general, $\mathrm{IO}_{3}{ }^{-}$is the dominant species in oxidizing environments, while $\mathrm{I}^{-}$becomes the main species in reducing conditions. In addition, molecular iodine $\left(\mathrm{I}_{2}\right)$ exists in low $\mathrm{pH}$ and in natural environment, organic iodine compounds might be present [5]. It is crucial to notice that iodine can exist in several forms even at the same time. Further, the speciation of iodine affects essentially its geochemical behaviour and interactions with natural materials [5-7] or synthetic solid sorbents developed for iodine removal $[8,9]$. To reliably assess the interaction of different remediation materials, it is essential to precisely control and survey the speciation of iodine.

In macro-concentrations, the speciation of iodine can be measured conventionally with a combination of chromatographic techniques (i.e. IC, LC or HPLC) and an appropriate detector, such as ICP-MS (inductively coupled plasma mass spectrometry) [10-15]. With radioactive samples, the availability of special instruments might be limited because of safety aspects. It is also rather common to perform experiments regarding iodine uptake with radioactive iodine tracers. Even though some experiments include alteration of iodine redox state, not all of the studies include or specify the verification of iodine speciation during the experiments or after the redox change. On the other hand, for 
the environmental samples regarding iodine speciation, the instant separation of two major iodine species already at the time of sampling in the field would be beneficial to prevent any possible redox state changes between the sampling and analysis.

Silver-impregnated activated carbons (Ag-GAC) have been used in iodide removal for decades [16-18] and these materials are readily commercially available. The uptake of iodide is based on the precipitation reaction with silver cation [16]. AgI has extremely low solubility $\left(K_{\mathrm{sp}}=8.5 \times 10^{-17}\right)$ compared to other silver halides, like $\mathrm{AgCl}\left(K_{\mathrm{sp}}=1.8 \times 10^{-10}\right)$ and $\mathrm{AgBr}\left(K_{\mathrm{sp}}=5.4 \times 10^{-13}\right)$. For the $\mathrm{AgIO}_{3}$, the solubility product is also much higher $\left(K_{\mathrm{sp}}=3.17 \times \mathrm{I}^{-8}\right)[19]$.

Based on the difference in the affinity of the two iodine species to silver, the separation of them can be obtained. Here, we demonstrate a simple method for separating iodide and iodate species from each other in liquid samples using a commercial Ag-GAC. While iodine separation from aqueous solution has been extensively studied in many studies (i.e. references [8] and [9]), usually studies are considering either total iodine removal or removal efficiency for different iodine species from contaminated water. Instead, Ag-GAC is selective only to one species of iodine $\left(\mathrm{I}^{-}\right)$and not to another $\left(\mathrm{IO}_{3}{ }^{-}\right)$. This high and reproducible separation performance can be utilized in the speciation analysis of iodine.

Our proposed method is especially suitable for the separation of iodate and iodide species of radioactive ${ }^{125}$ I measured with $\gamma$-detection, but it is not only limited to that but can be used for the separation of non-radioactive iodine species if combined with a suitable detector like for example ICP-MS. One advantage of the method is that it could be used already in the field for the separation of iodine species, while the analysis could be done in laboratory later on, avoiding possible changes in redox state of iodine. Another inorganic species of iodine is molecular iodine, $\mathrm{I}_{2}$, which is a stable species in acidic $\mathrm{pH}$. Iodine is routinely extracted in nonpolar solvents like chloroform [20,21] and the step could be easily added to our proposed methodology if needed. Organo-iodine compounds are beyond the scope of this particular study and if present require further separation not to interfere with the results of $\mathrm{I}^{-} / \mathrm{IO}_{3}{ }^{-}$separation.

Compared to a simple precipitation of $\mathrm{AgI}$ using silver salt like $\mathrm{AgNO}_{3}$, the silver-impregnated activated carbon provides an alternative approach and helps to avoid unwanted and disturbing co-precipitation or oxidation-reduction reactions. As a reference, the performance of Ag-GAC is compared with strong basic anion exchanger, which often is used to separate different anions, e.g. iodide and iodate.

\section{Experimental}

\section{Chemicals}

All reagents were of analytical grade (Alfa Aesar, SigmaAldrich, Riedel de Häen) and used without further purification. The radioactive ${ }^{125}$ I tracer was purchased from PerkinElmer. Silcarbon AG03 silver-impregnated carbon made from coconut shell (silver content $\sim 0.3 \mathrm{wt} \%$, specific surface area $1150 \mathrm{~m}^{2} \mathrm{~g}^{-1}$ ) was kindly supplied by Silcarbon Aktivkohle GmbH, Germany and used as received. Dowex ${ }^{\circledR}$ $1 \mathrm{X} 4$ Strong Anion Exchanger in chloride form (50-100 mesh) was purchased from Sigma-Aldrich and used without further pretreatment.

\section{Instrumentation}

In the experiments conducted with radioactive ${ }^{125}$ I tracer, the radioactivity was measured from $5 \mathrm{ml}$ aqueous samples using Perkin Elmer WizardTM 3" automated NaI-scintillation $\gamma$-detector with a 20 min counting time.

In the case of non-radioactive iodine, the concentrations of iodide and iodate were analysed using an anion-exchange chromatography column (Dionex AS11 4×250 mm analytical column and AG11 $4 \times 50 \mathrm{~mm}$ guard column) attached to an Agilent 1260 Infinity quaternary pump and autosampler HPLC-system connected to an Agilent 7800 ICP-MS via direct connection between the column and ICP nebulizer. The eluent was $50 \mathrm{mM}$ sodium hydroxide $(\mathrm{NaOH})$ and isocratic elution with flow rate of $0.8 \mathrm{ml} / \mathrm{min}$ was used. Argon gas was bubbled to the eluent container to minimize the concentration of dissolved carbon dioxide. The iodine species $\mathrm{I}^{-}$and $\mathrm{IO}_{3}{ }^{-}$were separated based on their retention times obtained from the standard solutions prepared from $\mathrm{KI}$ and $\mathrm{KIO}_{3}$. The quantification was done using external standards on the range $0-200 \mu \mathrm{g} \mathrm{L}{ }^{-1}$ of total iodine for both species and calculating the concentration from the peak areas. The ICP-MS was driven in the no-gas mode and the measured isotope was ${ }^{127}$ I. The quality control of measurements was done by measuring calibration blanks and standard samples $\left(5+5\right.$ and $50+50 \mu \mathrm{g} \mathrm{L}^{-1}$ of total iodine $\left.\mathrm{I}^{-}+\mathrm{IO}_{3}^{-}\right)$from separate dilution series after every calibration and between the sample measurements. The observed retention times remained stable and were $120 \mathrm{~s}$ for $\mathrm{IO}_{3}{ }^{-}$and $360 \mathrm{~s}$ for $\mathrm{I}^{-}$. A limit of detection (LOD) for HPLC-ICP-MS system was determined to be $0.5 \mu \mathrm{g} \mathrm{L}^{-1}$ and $0.2 \mu \mathrm{g} \mathrm{L}^{-1}$ for $\mathrm{I}^{-}$and $\mathrm{IO}_{3}^{-}$, respectively, by using repeated injection method and measuring 8 replicates of $1 \mu \mathrm{g} \mathrm{L}^{-1}$ calibration standard and calculating the LOD based on the literature [22]. 


\section{lodine speciation manipulation}

$\mathrm{KI}$ and $\mathrm{KIO}_{3}$ were used as analytes for $\mathrm{I}^{-}$and $\mathrm{IO}_{3}{ }^{-}$in the case of non-radioactive experiments, but radioactive ${ }^{125} \mathrm{I}$ was only available in the form of $\mathrm{Na}^{125} \mathrm{I}$. For this reason, the oxidation and reduction procedures were first tested with non-radioactive starting materials and using HPLC-ICP-MS to determine the yield of the reactions with different concentrations of oxidant and reducing agent. $\mathrm{NaOCl}$ and $\mathrm{NaHSO}_{3}$ were used to either oxidize iodine to $\mathrm{IO}_{3}{ }^{-}$or reduce to $\mathrm{I}^{-}$, respectively.

In order to obtain $\mathrm{IO}_{3}{ }^{-}$solutions, oxidation of $\mathrm{I}^{-}$solutions $\left(8 \times 10^{-7} \mathrm{M}\right)$ was achieved using $0.01-10 \mathrm{mM} \mathrm{NaOCl}$ in $10 \mathrm{mM} \mathrm{NaOH}$ for $24 \mathrm{~h}$. Similarly, $\mathrm{I}^{-}$was reduced from $\mathrm{IO}_{3}{ }^{-}$by using $0.01-10 \mathrm{mM} \mathrm{NaHSO}{ }_{3}$ in $20 \mathrm{mM} \mathrm{HCl}$ for $24 \mathrm{~h}$. The concentration of $\mathrm{I}^{-}$and $\mathrm{IO}_{3}{ }^{-}$were measured with HPLC-ICP-MS before and after the addition of oxidant or reductive agent.

Similar procedure was used for ${ }^{125} \mathrm{I}$, where the starting material was $\mathrm{Na}^{125} \mathrm{I}$, but in much lower concentrations $\left(\sim 10^{-11} \mathrm{M}\right)$ compared to non-radioactive iodine solutions. The appropriate concentrations of oxidant or reductant was decided based on the experiments performed with non-radioactive materials.

\section{Batch experiments}

Iodide and iodate uptake properties of Ag-GAC and strongly basic anion exchanger were studied with batch experiments to test the effect of the matrix solution to the uptake of iodate and iodide. Sample series were made for both iodine species as a function of $\mathrm{pH}$ and with interfering anions $\left(\mathrm{Cl}^{-}, \mathrm{NO}_{3}{ }^{-}\right.$, $\mathrm{SO}_{4}{ }^{2-}$ ) added as Na salt solutions in different concentrations (1-1000 $\mathrm{mM}$ for $\mathrm{Cl}^{-}, 1-100 \mathrm{mM}$ for the others).

In batch experiments, $20 \pm 1 \mathrm{mg}$ of adsorbent material (Ag-GAC or Dowex ${ }^{\circledR}$ 1X4 Strong Anion Exchanger) was weighed to a polyethylene vial and $10 \mathrm{ml}$ of test solution with appropriate iodine species were added. In the experiments where $\mathrm{pH}$ adjustment was needed, appropriate volumes of $0.1 \mathrm{M} \mathrm{NaOH}$ or $\mathrm{HNO}_{3}$ solutions were added to samples before the addition of iodine. The initial iodine concentrations were $8 \times 10^{-7} \mathrm{M}$ in experiments with non-radioactive iodine and in experiments with radioactive iodine the radioactivity of carrier-free ${ }^{125} \mathrm{I}$ was between $100-250 \mathrm{~Bq}$ for a sample corresponding to concentrations on the scale of $\sim 10^{-13} \mathrm{M}$. The samples were equilibrated for $24 \pm 2 \mathrm{~h}$ and solid and liquid phases were separated by centrifuging ( 3000 $\mathrm{G}, 10 \mathrm{~min}$ ) followed by filtering of $6 \mathrm{ml}$ fraction with a 0.2 $\mu \mathrm{m}$ syringe filter (PVDF LC. Arcodisc, Gellman Sciences). The equilibrium $\mathrm{pH}$ was measured from the remaining supernatant using a Ross combined electrode. In the case of non-radioactive isotope, $1 \mathrm{ml}$ of filtered solution was placed into glass HPLC-vial and analysed with HPLC-ICP-MS. In the case of radioactive ${ }^{125} \mathrm{I}, 5 \mathrm{ml}$ of filtered solution was pipetted to a scintillation vial and analysed with Wallac 1480 Wizard 3" automated NaI-scintillation detector.

The sorption percentages were calculated from the concentrations obtained from the solution analysis using Eq. (1).

$S \%=\frac{c_{i}-c_{f}}{c_{i}} \times 100 \%$

where $c_{i}=$ initial concentration and where $c_{f}=$ final concentration of iodide/iodate in the solution.

In the case of radioactivity measurements, the sorption percentages were counted from the net count rates using Eq. (2).

$S \%=\frac{R_{i}-R_{f}}{R_{i}} \times 100 \%$

where $R_{i}=$ initial net count rate and where $R_{f}=$ final net count rate in the solution.

\section{Column experiments}

Column studies were performed with a simulant containing a high excess of $\mathrm{SO}_{4}{ }^{2-}, \mathrm{Cl}^{-}$and $\mathrm{NO}_{3}{ }^{-}$compared to iodine species $\left(\mathrm{I}^{-}, \mathrm{IO}_{3}{ }^{-}\right)$concentrations. A self-prepared simulant with a simplified composition of Artificial Seawater ASTM D1141-98 [23] was used, described in Table 1.

In total, two identical column experiment sets were run with five different $\mathrm{I}^{-} / \mathrm{IO}_{3}{ }^{-}$concentration ratios in normal uncontrolled laboratory atmosphere. The columns were packed into open-cut $1 \mathrm{ml}$ polyethylene disposable pipettes (i.d. 4 mm) (Fig. 1) with a slurry containing $0.2 \mathrm{~g}$ of AgGAC and $5 \mathrm{ml}$ of $10 \mathrm{mM} \mathrm{NaNO}_{3}$. After the preparation, $5 \mathrm{ml}$ of test solution was let to flow through the column to replace the solution remaining form the packing before collecting a $10 \mathrm{ml}$ sample to a separate vial. The average flow velocity was $2.7 \pm 1.0 \mathrm{ml} / \mathrm{min}$. Samples of test solutions were analyzed with HPLC-ICP-MS before and after the contact

Table 1 The composition of the artificial sea water used in the experiments

\begin{tabular}{ll}
\hline Component & $\begin{array}{l}\text { Concen- } \\
\text { tration } \\
(\mathrm{mM})\end{array}$ \\
\hline $\mathrm{Na}^{+}$ & 480 \\
$\mathrm{~K}^{+}$ & 10 \\
$\mathrm{Mg}^{2+}$ & 55 \\
$\mathrm{Ca}^{2+}$ & 10 \\
$\mathrm{Cl}^{-}$ & 560 \\
$\mathrm{Br}^{-}$ & 1 \\
$\mathrm{SO}_{4}{ }^{2-}$ & 30 \\
$\mathrm{pH}^{-}$ & 7.7 \\
\hline
\end{tabular}




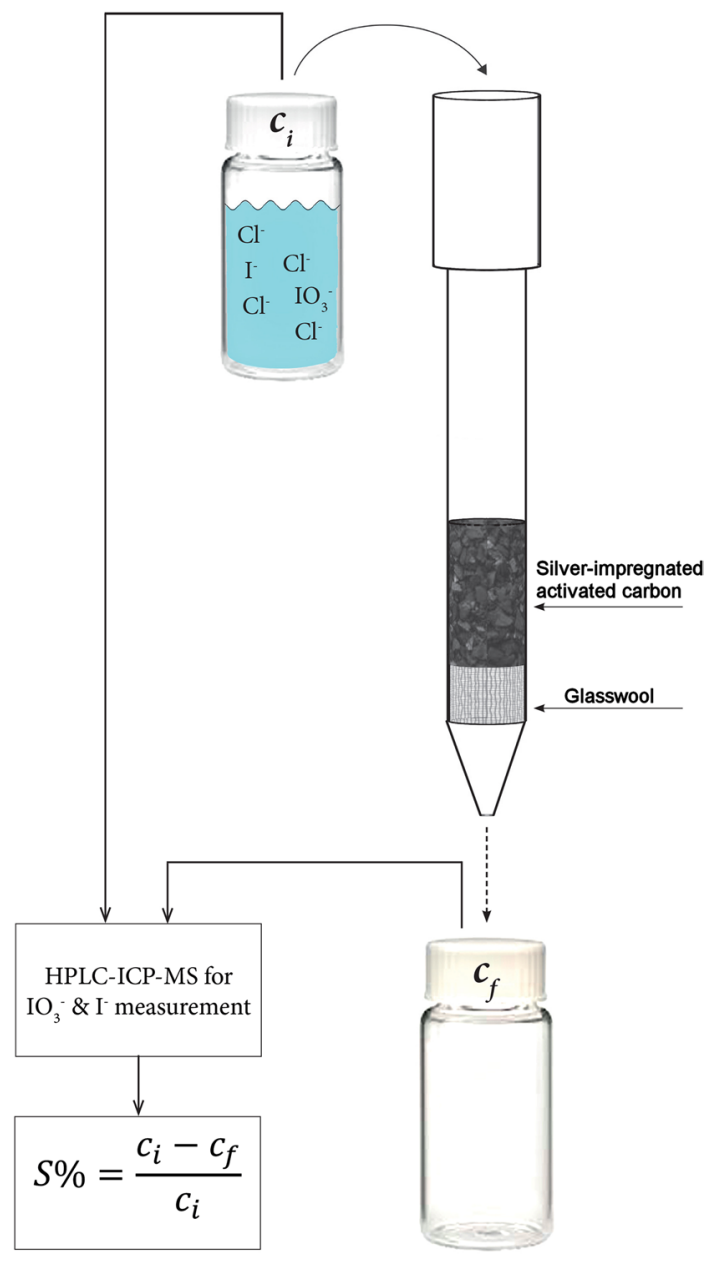

Fig. 1 The experimental setup of column studies

with column and sorption percentages were calculated with Eq. (1).

\section{Results and discussion}

\section{lodine speciation manipulation}

Iodine speciation is a crucial factor affecting the element's chemical behaviour and thus its behaviour in purification processes and fate in environment. Two procedures for iodine speciation manipulation were used to change the oxidation state of iodine. The procedures were tested with ${ }^{127} \mathrm{IO}_{3}{ }^{-}$and ${ }^{127} \mathrm{I}^{-}$to ensure the suitability for the redox manipulation of radioactive ${ }^{125} \mathrm{I}$. For ${ }^{127} \mathrm{I}$, solid starting materials $\mathrm{KIO}_{3}$ and $\mathrm{KI}$ are readily available but for radioactive tracers the iodine is quite often only available in the form of $\mathrm{K}^{125} \mathrm{I}$. Table 2 shows the concentrations of both $\mathrm{I}^{-}$and $\mathrm{IO}_{3}{ }^{-}$species for all the samples with different concentration of redox agents $\mathrm{NaOCl}$ and $\mathrm{NaHSO}_{3}$ used for oxidation and
Table 2 Manipulation of iodine redox state

\begin{tabular}{llllc}
\hline $\begin{array}{l}\text { Concentration of redox } \\
\text { agent }(\mathrm{mM})\end{array}$ & \multicolumn{2}{l}{$\begin{array}{l}\text { Iodine concentration } \\
\left(\mu \mathrm{g} \mathrm{L}^{-1}\right)\end{array}$} & Conversion (\%) \\
\cline { 2 - 4 } & & $\mathrm{I}^{-}$ & $\mathrm{IO}_{3}^{-}$ & \\
\hline $\mathrm{NaOCl}$ & 0 & 96 & - & 0 \\
& 2 & - & 94 & 97.3 \\
& 10 & 1 & 93 & 96.1 \\
& 20 & 5 & 93 & 97.2 \\
$\mathrm{NaHSO}_{3}$ & 0 & - & 82 & 0 \\
& 0.2 & 84 & 1 & 103.2 \\
& 1 & 79 & 1 & 96.5 \\
& 2 & 71 & 1 & 86.5 \\
\hline
\end{tabular}

The conversion (\%) is calculated based on the measured concentration of $\mathrm{IO}_{3}{ }^{-} / \mathrm{I}^{-}$compared with the initial concentration. The concentrations of different iodine species were measured by HPLC-ICP-MS

reduction, respectively, of iodine. It seems that oxidation in basic conditions is reproducible as $>95 \%$ of $\mathrm{I}^{-}$was oxidized to $\mathrm{IO}_{3}{ }^{-}$in all of the samples.

What should be noted, is that also raising concentrations of $\mathrm{I}^{-}$were detected with rising concentration of $\mathrm{NaOCl}$ which seems a bit controversial. It might also be just measurement artefact. On the other hand, reduction of $\mathrm{IO}_{3}{ }^{-}$to $\mathrm{I}^{-}$worked fine although decreasing efficiency was observed with rising concentration of $\mathrm{NaHSO}_{3}$. One reason could be stabilization of molecular iodine with the decreasing $\mathrm{pH}$ [24]. No extra peaks were detected in chromatograms, although the chromatogram for a sample after the reduction of $\mathrm{IO}_{3}{ }^{-}$to $\mathrm{I}^{-}$showed tailing (see supplementary information).

\section{Batch experiments}

The effect of solution matrix elements on iodine uptake of Dowex 1X4 Strong Basic Anion exchanger and SilCarbon Ag-GAC were studied with a series of batch experiments. For Ag-GAC, also the effect of $\mathrm{pH}$ was studied. The experiments with Dowex were done only with macroscopic iodine concentrations $\left(8 \times 10^{-7} \mathrm{M}\right)$, while the experiments with $\mathrm{Ag}$ GAC were done with both macroscopic and trace iodine concentrations using radioactive ${ }^{125} \mathrm{I}^{-}$and ${ }^{125} \mathrm{IO}_{3}{ }^{-}\left(\sim 10^{-13} \mathrm{M}\right)$.

Dowex 1X4 Strong Basic Anion exchanger showed considerably higher affinity towards $\mathrm{I}^{-}$than $\mathrm{IO}_{3}^{-}$(Fig. 2) as expected, but in low matrix concentrations also notable fraction of $\mathrm{IO}_{3}{ }^{-}$was removed from the solution. With raising matrix concentrations, the uptake of both iodine species declined, the effect being more drastic for $\mathrm{IO}_{3}{ }^{-}$. The results show that Dowex Strong Basic Anion Exchanger does not show enough of selectivity to either of iodine species $\left(\mathrm{I}^{-}\right.$, $\left.\mathrm{IO}_{3}{ }^{-}\right)$to be used as analytical tool for ${ }^{125} \mathrm{I}$ in the conditions of the conducted batch experiments. 


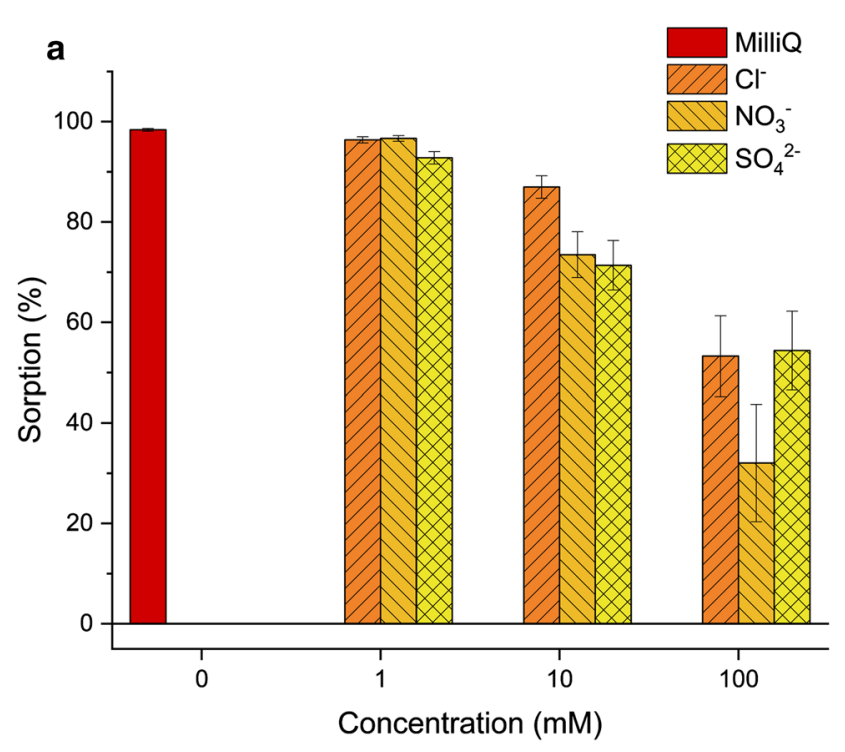

Fig. 2 The sorption of $\mathrm{I}^{-}$(a) and $\mathrm{IO}_{3}^{-}$(b) sorption to Dowex Strong Basic Anion exchanger in different matrices. The iodine measurements were done with HPLC-ICP-MS and equilibrium pH's were

The identical experiments in macroscopic and trace iodine concentrations were done with Ag-GAC (Fig. 3). The $\mathrm{I}^{-}$removal was almost $100 \%$, while the uptake of $\mathrm{IO}_{3}{ }^{-}$was negligible in the range of $1-100 \mathrm{mM}$ for all competing ions. Even high concentration of another halide, $\mathrm{Cl}^{-}$, did not reduce the $\mathrm{I}^{-}$uptake significantly, as it stayed as high as $97.3 \pm 0.1 \%$ even in $1000 \mathrm{mM} \mathrm{Cl}^{-}$matrix. In MilliQ water, the uptake was lower, although the samples showed a high variation. We suspect this is due to the degradation of the $\mathrm{Ag}-\mathrm{GAC}$ material itself in such a low ionic strength solution but was not furthermore studied because such a pure

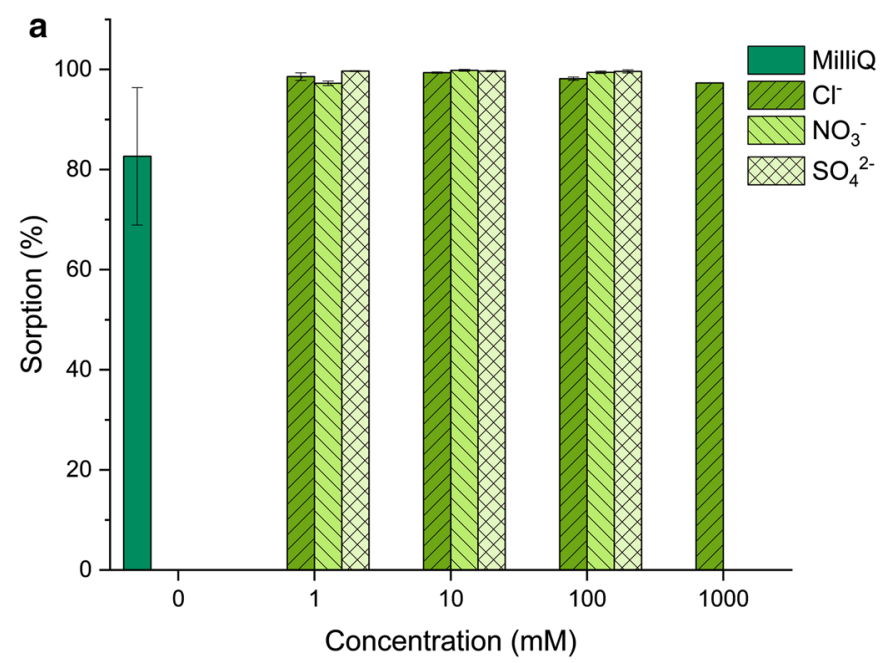

Fig. 3 The effect of concentration of different competing ions to ${ }^{127} \mathrm{I}^{-}$ (a) and ${ }^{127} \mathrm{IO}_{3}^{-}$(b) sorption (total iodine concentration $8 \times 10^{-7} \mathrm{M}$ ) to $\mathrm{Ag}-\mathrm{GAC}$. The iodine measurements were done with HPLC-ICP-MS

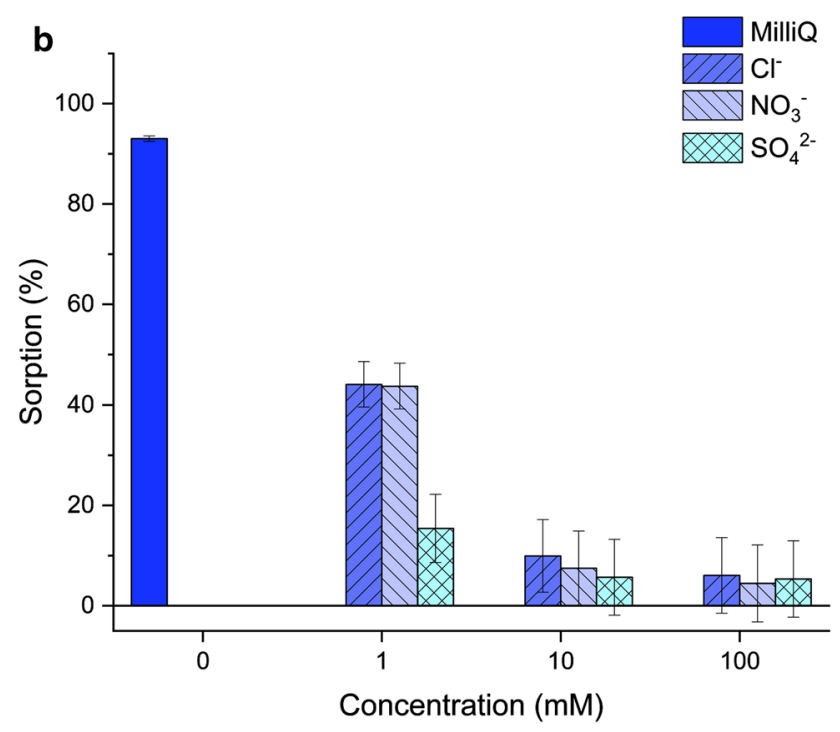

4.8-5.9. The error bars show the uncertainty of individual sample measurements caused by the uncertainty of the analysis method (see supplementary information for the detailed description). $(\mathrm{n}=1)$

analysis matrix is not relevant from the method application point-of-view.

The experiments with trace concentration of iodide showed somewhat different results (Fig. 4a) compared to macroscopic concentrations. In MilliQ water the iodide removal was $97.3 \pm 1.7 \%$ but it decreased to $71.8 \pm 2.0 \%$ in $1000 \mathrm{mM} \mathrm{Cl}^{-}$. With other ions and in lower $\mathrm{Cl}^{-}$concentrations the removal percentages were rather same regardless of iodine concentrations.

In theory, the competition between $\mathrm{Cl}^{-}$and $\mathrm{I}^{-}$can be described by the Eq. (3).

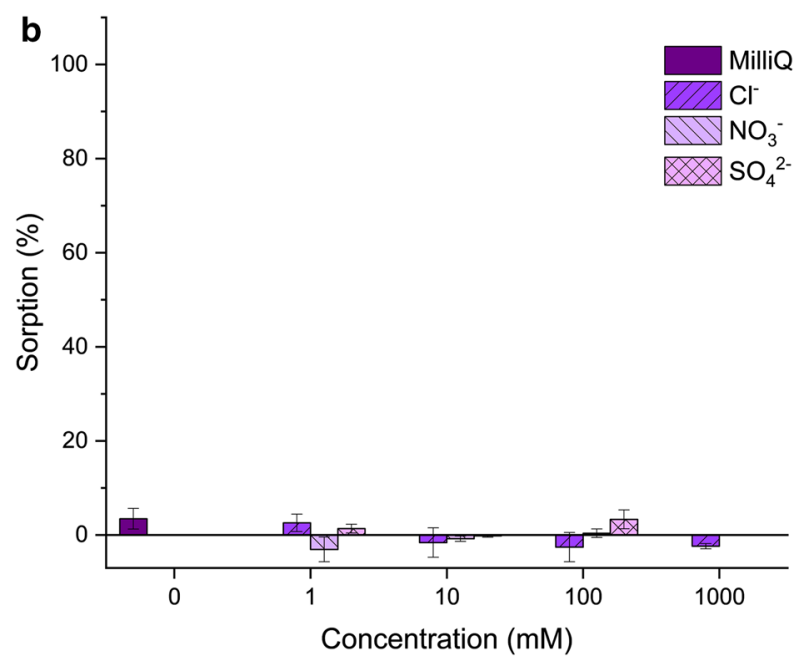

and equilibrium pH's were 7.2-8.5. Results represent the mean values of parallel samples and error bars show the standard deviation. $(n=3)$ 


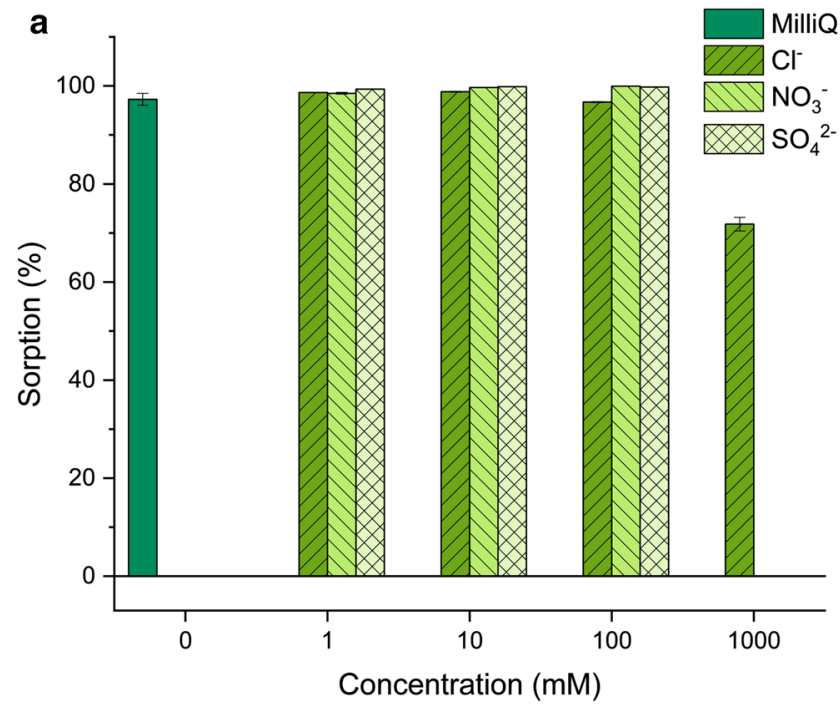

Fig. 4 The effect of concentration of different ions to ${ }^{125} \mathrm{I}^{-}$(a) and ${ }^{125} \mathrm{IO}_{3}^{-}$(b) sorption (total iodine concentration $\sim 10^{-13} \mathrm{M}$ ) to AgGAC. The iodine measurements were done by NaI-scintillation

$A g C l(s)+I^{-}(a q) \leftrightarrow A g I(s)+C l^{-}(a q)$

The reaction occurs because of much lower solubility of $\mathrm{AgI}$ compared to $\mathrm{AgCl}$ but only proceeds as long as $\mathrm{Cl}^{-} / \mathrm{I}^{-}$molar ratio is less than $2.1 \times 10^{6}$ [25]. In the case of the batch experiments of our current study, the $\mathrm{Cl}^{-} / \mathrm{I}^{-}$ratio was $1 \times 10^{13}$ in $1000 \mathrm{mM} \mathrm{Cl}^{-}$solution. This is several orders of magnitude over the equilibrium constant of Eq. (3) and no AgI should precipitate. However, iodide adsorption can occur even in these unfavourable $\mathrm{Cl}^{-} / \mathrm{I}^{-}$ratios because of formation of mixed crystal silver halides [16]. $\mathrm{AgI}$ and $\mathrm{AgCl}$ form mixed crystals to the extent of $1-5 \mathrm{~mol} \%[26,27]$, which is much higher compared to the $\mathrm{Cl}^{-} / \mathrm{I}^{-}$ratios in our study and can explain the iodide sorption in the conditions of the batch experiments.

Regardless of the matrix solution, the results looked similar for ${ }^{125} \mathrm{IO}_{3}^{-}$(Fig. 4b) as the results of experiments with macroscopic $\mathrm{IO}_{3}{ }^{-}$concentrations.

The effect of $\mathrm{pH}$ on $\mathrm{IO}_{3}{ }^{-}$removal was studied in a solution containing $10 \mathrm{mM}$ of all $\mathrm{NaCl}, \mathrm{NaNO}_{3}$ and $\mathrm{Na}_{2} \mathrm{SO}_{4}$ (Fig. 5). At very low $\mathrm{pH}, \mathrm{IO}_{3}{ }^{-}$concentrations decreased ( $\mathrm{pH} 3.0: 45 \%, \mathrm{pH} 3.5: 14 \%)$ and this is most probably explained by the formation of volatile $\mathrm{I}_{2}$. In samples with a $\mathrm{pH}$ value higher than 5.0, where the probability of $\mathrm{IO}_{3}{ }^{-} / \mathrm{I}_{2}$ transition is not favoured, negligible (or very low) iodate removal was observed. In the case of $\mathrm{I}^{-}$, no iodide was detected on $\mathrm{pH}$ range between 2.9 and 9.4 (18 samples, not shown in graph).

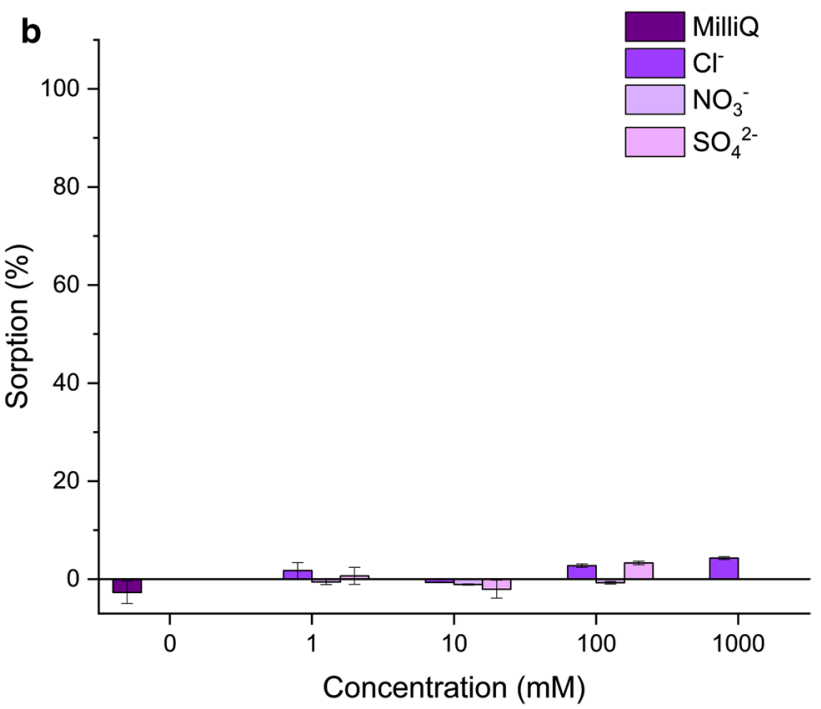

$\gamma$-detector and equilibrium pH's were 6.2-7.8. Results represent the mean values of parallel samples and error bars show the standard deviation. $(\mathrm{n}=2)$

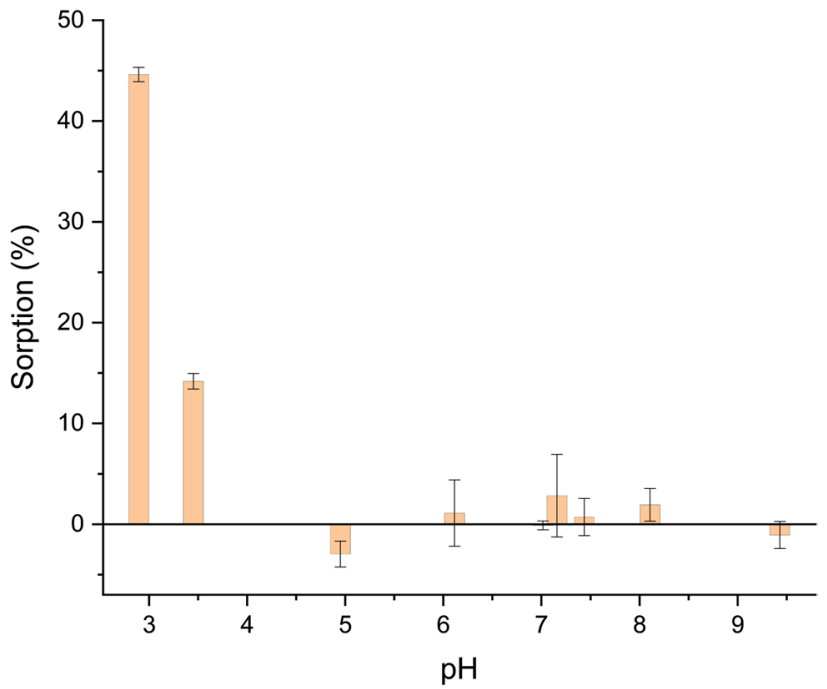

Fig. 5 The effect of $\mathrm{pH}$ to $\mathrm{IO}_{3}{ }^{-}$sorption to $\mathrm{Ag}-\mathrm{GAC}$ in solution containing $10 \mathrm{mM} \mathrm{NaCl}, 10 \mathrm{mM} \mathrm{NaNO}_{3}$ and $10 \mathrm{mM} \mathrm{Na}_{2} \mathrm{SO}_{4}$. The iodine measurements were done with HPLC-ICP-MS. Results represent the mean values of parallel samples and error bars show the standard deviation. $(n=2)$

\section{Column experiments}

The batch experiments showed high selectivity of Ag-GAC to $\mathrm{I}^{-}$species over $\mathrm{IO}_{3}{ }^{-}$. In these experiments the contact time was rather long, $24 \mathrm{~h}$, and system was expected to be in equilibrium. To evaluate the performance in dynamic conditions more relevant to speciation determining applications, a series of column experiments were carried (Fig. 6). With a 


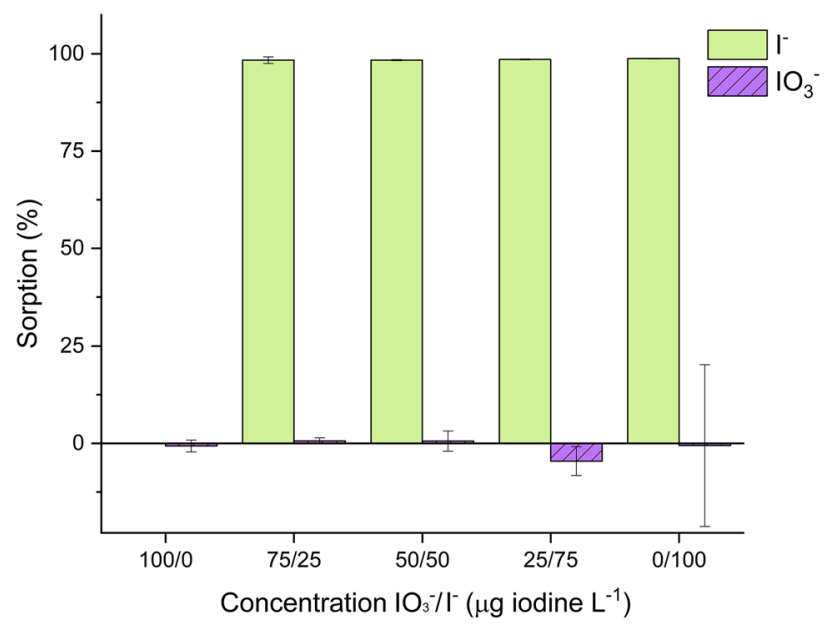

Fig. 6 The iodide (green columns) and iodate (purple columns) removal from artificial seawater with $0.2 \mathrm{~g}$ columns of Ag-GAC. Results represent the mean values of parallel samples and error bars show the standard deviation. Note that some of the error bars are not showing due small deviation between parallel samples. $(n=2)$

rather high flow velocity of $3 \mathrm{ml} / \mathrm{min}$, almost $100 \%$ of iodide was retained in the column. With iodate, the opposite was observed and almost all of this species was passed through the column. These results not only demonstrate the high selectivity of silver to iodide even with high concentrations of competing ions like $\mathrm{Cl}^{-}$, but also the fast kinetics of the reaction that is needed for analytical applications.

\section{Conclusions}

We have shown that Ag-GAC can be readily used in quantitative separation of $\mathrm{I}^{-}$and $\mathrm{IO}_{3}{ }^{-}$species. Iodide is adsorbed efficiently on the material while iodate remains in solution. Iodide and iodate species fractions can be easily calculated if the total iodine concentration is known before and after the contact. However, in simultaneous high $\mathrm{Cl}^{-}$concentrations $(>100 \mathrm{mM})$ and trace level iodide concentrations, also the competition between $\mathrm{Cl}^{-}$and $\mathrm{I}^{-}$should be taken into account. In $\mu \mathrm{M}$ iodide concentration level even as high as $1000 \mathrm{mM} \mathrm{Cl}^{-}$did not interfere the $\mathrm{I}^{-} / \mathrm{IO}_{3}{ }^{-}$separation. Compared with other studies regarding iodine removal from aqueous solution (i.e. refs. [8] and [9]), this approach only removes iodide and not iodate, offering a tool for the separation between the two iodine species.

Chemically stable and commercially available Ag-GAC offers a simple way to perform $\mathrm{I}^{-} / \mathrm{IO}_{3}{ }^{-}$species separation in variable matrices, even in the case of high salt content. No special equipment for separation is needed as long as total iodine concentration can be measured by some analysis method. Especially suitable this method is in the case of using radioactive iodine tracers, i.e. ${ }^{125} \mathrm{I}$, which can easily be detected. Moreover, the proposed method can be used in the field to achieve the separation of iodine species right after the sampling without the risk of sample alteration because of uncontrolled reduction and oxidation reactions between the sampling and the analysis. This could be beneficial even with non-radioactive iodine analysis.

The method relies on the highly favoured interaction between silver in activated carbon and iodide, while iodate does not have notable affinity towards the material. The separation was shown to be quantitative both in batch and column type separations. This study does not concern organic iodine compounds or molecular iodine. Another or modified approach is needed if those are expected to be present in samples. On the other hand, the proposed methodology can be readily combined with other separation techniques, e.g. liquid-liquid extraction, for comprehensive iodine speciation analysis even when other iodine species like organic iodine compounds and elemental iodine are present.

Acknowledgements Open access funding provided by University of Helsinki including Helsinki University Central Hospital. Financial support from the Doctoral Programme in Chemistry and Molecular Sciences (CHEMS) at the University of Helsinki is gratefully acknowledged.

Open Access This article is licensed under a Creative Commons Attribution 4.0 International License, which permits use, sharing, adaptation, distribution and reproduction in any medium or format, as long as you give appropriate credit to the original author(s) and the source, provide a link to the Creative Commons licence, and indicate if changes were made. The images or other third party material in this article are included in the article's Creative Commons licence, unless indicated otherwise in a credit line to the material. If material is not included in the article's Creative Commons licence and your intended use is not permitted by statutory regulation or exceeds the permitted use, you will need to obtain permission directly from the copyright holder. To view a copy of this licence, visit http://creativecommons.org/licenses/by/4.0/.

\section{References}

1. Bürgi H, Schaffner T, Seiler J (2001) The toxicology of iodate: a review of the literature. Thyroid 11:449-456. https://doi. org/10.1089/105072501300176408

2. Joint F, WHO Expert Committee on Food Additives, World Health Organization (1991) Evaluation of certain food additives and contaminants: thirty-seventh report of the Joint FAO

3. Zhang S, Xu C, Creeley D, Ho Y, Li H, Grandbois R, Schwehr KA, Kaplan DI, Yeager CM, Wellman D (2013) Iodine-129 and iodine-127 speciation in groundwater at the Hanford Site, US: iodate incorporation into calcite. Environ Sci Technol 47:96359642. https://doi.org/10.1021/es401816e

4. Hjerpe T, Ikonen AT, Broed R (2010) Biosphere assessment report 2009. Posiva Report 2010-03

5. Xu C, Kaplan DI, Zhang S, Athon M, Ho Y, Li H, Yeager CM, Schwehr KA, Grandbois R, Wellman D (2015) Radioiodine sorption/desorption and speciation transformation by subsurface sediments from the Hanford Site. J Environ Radioact 139:43-55. https ://doi.org/10.1016/j.jenvrad.2014.09.012 
6. Whitehead D (1984) The distribution and transformations of iodine in the environment. Environ Int 10:321-339. https://doi. org/10.1016/0160-4120(84)90139-9

7. Kaplan DI, Serne RJ, Parker KE, Kutnyakov IV (2000) Iodide sorption to subsurface sediments and illitic minerals. Environ Sci Technol 34:399-405. https://doi.org/10.1021/es990220g

8. Levitskaia TG, Chatterjee S, Arey BW, Campbell EL, Hong Y, Kovarik L, Peterson JM, Pence NK, Romero J, Shutthanandan V (2016) RedOx-controlled sorption of iodine anions by hydrotalcite composites. RSC Advances 6:76042-76055. https://doi. org/10.1039/C6RA13092E

9. Parker KE, Golovich EC, Wellman DM (2014)Iodine adsorption on ion-exchange resins and activated carbons: batch testing. PNNL-23730. https://doi.org/10.2172/1163822

10. Salov V, Yoshinaga J, Shibata Y, Morita M (1992) Determination of inorganic halogen species by liquid chromatography with inductively coupled argon plasma mass spectrometry. Anal Chem 64:2425-2428. https://doi.org/10.1021/ac00044a021

11. Chen Z, Megharaj M, Naidu R (2007) Speciation of iodate and iodide in seawater by non-suppressed ion chromatography with inductively coupled plasma mass spectrometry. Talanta 72:18421846. https://doi.org/10.1016/j.talanta.2007.02.014

12. Shimamoto YS, Itai T, Takahashi Y (2010) Soil column experiments for iodate and iodide using K-edge XANES and HPLC-ICP-MS. J Geochem Explor 107:117-123. https://doi. org/10.1016/j.gexplo.2009.11.001

13. Han X, Cao L, Cheng H, Liu J, Xu Z (2012) Determination of iodine species in seaweed and seawater samples using ion-pair reversed phase high performance liquid chromatography coupled with inductively coupled plasma mass spectrometry. Anal Methods 4:3471-3477. https://doi.org/10.1039/C2AY25871D

14. Söderlund M, Virkanen J, Aromaa H, Gracheva N, Lehto J (2017) Sorption and speciation of iodine in boreal forest soil. J Radioanal Nucl 311:549-564. https://doi.org/10.1007/s10967-016-5022-z

15. Cui W, Hou H, Chen J, Yu X, Guo Y, Tao Z, Deng T, Chen Y, Belzile N (2019) The speciation analysis of iodate and iodide in high salt brine by high performance liquid chromatography and inductively coupled plasma mass spectrometry. J Anal At Spectrom 34:1374-1379. https://doi.org/10.1039/C9JA00121B

16. Ho PC, Kraus KA (1981) Adsorption on inorganic materialsVIII: adsorption of iodide on AgCl-filled carbon. J Inorg Nucl Chem 43:583-587. https://doi.org/10.1016/0022-1902(81)80507 $-6$
17. Hoskins JS, Karanfil T, Serkiz SM (2002) Removal and sequestration of iodide using silver-impregnated activated carbon. Environ Sci Technol 36:784-789. https://doi.org/10.1021/es010972m

18. Karanfil T, Moro E, Serkiz S (2005) Development and testing of a silver chloride-impregnated activated carbon for aqueous removal and sequestration of iodide. Environ Technol 26:1255-1262. https ://doi.org/10.1080/09593332608618595

19. Haynes WM (2014) CRC handbook of chemistry and physics. CRC press

20. Tunali N, Erten H, Kinikoğlu S, Gümüş Ş (1979) Solvent extraction behaviour of iodine and bromine in aqueous-organic systems, analogy with radioactive decay. J Radioanal Nucl 49:225-237. https://doi.org/10.1007/BF02519913

21. Hou X, Dahlgaard H, Rietz B, Jacobsen U, Nielsen S, Aarkrog A (1999) Determination of chemical species of iodine in seawater by radiochemical neutron activation analysis combined with ionexchange preseparation. Anal Chem 71:2745-2750. https://doi. org/10.1021/ac9813639

22. Wells G, Prest H, Russ C (2011) Signal, noise, and detection limits in mass spectrometry. Technical Note for Agilent Technologies Inc

23. Standard A (2013) D1141-98: standard Practice for the Preparation of Substitute Ocean Water. ASTM International, West Conshohocken. https://doi.org/10.1520/D1141-98R13

24. Takeno, N (2005) Atlas of Eh-pH diagrams-intercomparison of thermodynamic databases. Geological Survey of Japan, Open File Report 419

25. Zhang H, Gao X, Guo T, Li Q, Liu H, Ye X, Guo M, Wu Z (2011) Adsorption of iodide ions on a calcium alginate-silver chloride composite adsorbent. Colloids Surf A 386:166-171. https://doi. org/10.1016/j.colsurfa.2011.07.014

26. Farnell GC, Burton PC, Hallama R (1950) LI. The fluorescence of silver halides at low temperatures: part II. Mixed crystals of silver halides. London, Edinburgh Dublin Philosoph Magaz J Sci 41:545-556. https://doi.org/10.1080/14786445008561120

27. Oczkowski H (1978) Thermoluminescence in $\mathrm{Ag}(\mathrm{Cl}, \mathrm{I})$ mixed crystals. J Lumin 17:113-120. https://doi.org/10.1016/00222313(78)90031-5

Publisher's Note Springer Nature remains neutral with regard to jurisdictional claims in published maps and institutional affiliations. 